\title{
Impairment of NK Cell Mediated Immune Surveillance Against Acute Myeloid Leukemia
}

\author{
(D) Mohammed TAHA \\ Department of Pharmacology and Medical Sciences, Al-Azhar University of Gaza, Faculty of Pharmacy, Gaza-Palestine
}

\begin{abstract}
SUMMARY
Natural killer (NK) cells are cytotoxic lymphocytes contributing in innate immune responses that recognize and kill virus-infected and tumor cells without prior stimulation. Several clinical trials have indicated that NK cell-based immunotherapy represents a promising antitumor immunotherapeutic approach due to their key role in mediating graft versus leukemic effect against hematological malignancies, particularly acute myeloid leukemia. However, the antitumor activity of NK cells is inhibited as a result to immune-evasion mechanisms developed by malignant cells through alterations in the expression of activating and inhibitory receptors and their ligands, as well as secretion of soluble NK-inhibitory mediators. Until now, the exact molecular mechanisms involved in these alterations are still not defined.

Keywords: Immune evasion of acute myeloid leukemia; natural killer cells; natural killer cytotoxicity; natural killer cell immunosurveillance.

Copyright $\odot$ 2022, Turkish Society for Radiation Oncology
\end{abstract}

\section{Introduction}

Natural killer (NK) cells are lymphocytes of the innate immune system which have the ability to recognize tumors and virus-infected cells without prior specific sensitization. [1,2] NK cell functions are regulated by the expression of numerous inhibitory and activating receptors which bind to ligands on healthy or transformed cells.[1-3] The antitumor activity of NK cells is mediated through direct cytotoxic function as well as regulation of other immune cells by cytokine-secreting function. NK cells play a key role in mediating graft versus leukemic (GvL) effect against hematological malignancies, particularly acute myeloid leukemia (AML).[4,5] However, tumor cells can develop immunosuppressive mechanisms to escape NK cell-mediated immunity. Hence, maintaining or improving NK cell performance is considered a major challenge. In this review, we focus on the different mechanisms involved in the evasion of hematological malignancies from NK cells surveillance. Futhermore, we will mention the different approaches used to restore and improve the efficacy of anti-tumor function of NK cells against hematological malignancies.

\section{NK Cell Biology}

NK cells are lymphocytes arising from the lymphoid origin which are considered as the third largest population of lymphocytes following $\mathrm{T}$ and $\mathrm{B}$ cells encompassing approximately $10-15 \%$ of all peripheral blood lymphocytes.[6] However, NK cells are considered as critical cells of the innate immune system due to their ability to kill the target cells directly without specific immunization. [3,7] Based on the expression of CD56 molecule, NK cells are defined as CD56 ${ }^{+}$lymphocytes. [6] Phenotypically, NK cells can be divided into many subsets based on the surface expression of CD56, 
CD16, inhibitory receptors and/or activating receptors. [6] In general, the major subpopulations of NK cells are $\mathrm{CD} 56^{\text {bright }} \mathrm{CD} 16^{-/+}$(5-10\% of NK cells) and CD56 $6^{\text {dim }}$ CD16 ${ }^{+} \mathrm{NK}$ cells $(90-95 \%$ of NK cells). [6,8]

\section{NK Cell Cytotoxicity}

NK cells play a key role in immuno-surveillance and host defense against certain virus-infected or transformed cells mediated by direct cytolysis as well as regulation of the effector functions of other cytotoxic immune cells.[9-11] NK cell functions are controlled by a balance between activating and inhibitory signals provided by a varied group of activating receptors as (NKG2D, DNAM-1, NKp30, NKp44, and NKp46) and inhibitory receptors as NKG2A.[12] In general, NK cells can recognize abnormal cells through two models: Missing-self recognition and stress-induced recognition because abnormal cells as tumor cells can change their surface phenotype by losing the expression of human leukocyte antigen (HLA) class I molecules and/or upregulating damage-associated proteins. [13] Numerous damage-associated proteins have been expressed by tumor cells such as MICA and MICB binding with NKG2D, ligands of NKp30 as B7-H6, a mixed-lineage leukemia protein which is a ligand of NKp44, and CD155 and CD112 which interact with DNAM-1.[14] Consequently, NK cell activating receptors bind with their specific ligands expressed on the target cells resulting in lysis of their target cells. Alongside their activation by tumor cells and pathogens, NK cells can be directly or indirectly regulated through signals from other immune cells such as dendritic cells (DCs), macrophages, $\mathrm{CD}^{+} \mathrm{T}$ cells during the immune response.[14] Then, activated NK cells have the ability to kill their target cells though a variety of mechanisms, including cytolytic granule-dependent exocytosis pathway, signaling through the tumor necrosis factor (TNF) death receptor family members such as FAS (CD95) and TNF-related apoptosis-inducing ligand, the release of cytokines IFN- $\gamma$ and TNF- $\alpha$, and antibody dependent cell cytotoxicity (ADCC) via CD16. [15] Besides the cytotoxicity mediated by NK cells, immune response can be regulated by NK cells through the recruitment of other immune cells.

\section{NK Cells and AML}

Leukemias are cancers starting in cells that would normally develop into different types of blood cells. AML, one type of leukemias, is a heterogeneous clonal disor- der of HSC characterized by accumulation of immature, non-functional myeloid precursors (blasts) in the bone marrow and blood without the ability to differentiate normally and to respond to normal regulators of proliferation.[16] In general, patients with newly diagnosed AML, cytotoxic chemotherapy results in CR in approximately $60-80 \%$.[17] However, most of them relapse and about $40-45 \%$ of patients achieving CR remain alive at 5 years. To minimize the relapse and improve the survival rate of in patients, immunotherapy is used in combination with standard therapy.[18,19] NK cells play a principal role in the immunosurveillance of hematological malignancies by direct and indirect killing of tumor cells. Several clinical trials have been used NK cells as adoptive immunotherapy based on the alloreactivity of donor's NK cells to treat the hematological malignancies and solid tumors.[20-25] However, tumor cells can develop various mechanisms to escape immunosurveillance of NK cell and other effector cells.[26,27]

\section{Mechanisms of AML Escape from NK Cell Immunity}

Although the cytotoxic activity of NK cells against leukemia cells and their beneficial role in immunotherapy, many tumors including AML can evade the immunosurveillance of NK cell by destroying the precise balance between inhibitory and activating signals. [2832] Commonly, AML cells are able to escape NK cell immunosurveillance through various mechanisms: i) alteration of NK cells, ii) immunosuppressive properties of AML cells, and iii) interactions with other immune cells (Fig. 1).

\section{Alterations of NK Cell By AML}

AML cells are capable to alter the expression of NK cell receptors and their ligands, resulting in a significant impairment of NK cell functions, however, the molecular mechanisms responsible for these alterations are still unknown.

\section{Alterations of the Expression of NK Cell Receptors}

Several reports have shown a clear decrease in the expression of NK activating receptors on circulating NK cells of AML patients such as natural cytotoxic receptors, NCRs (NKp30, NKp44 and NKp46), NKG2D, and DNAM-1.[28,30,31,33-35] These alterations are associated with impaired anti-leukemic activity of NK cells, a decreased cytokine production, and risk of tumor relapse. Notably, Fauriat et al.,[30] (2007) showed that NCRs downregulation on NK cells was associated 


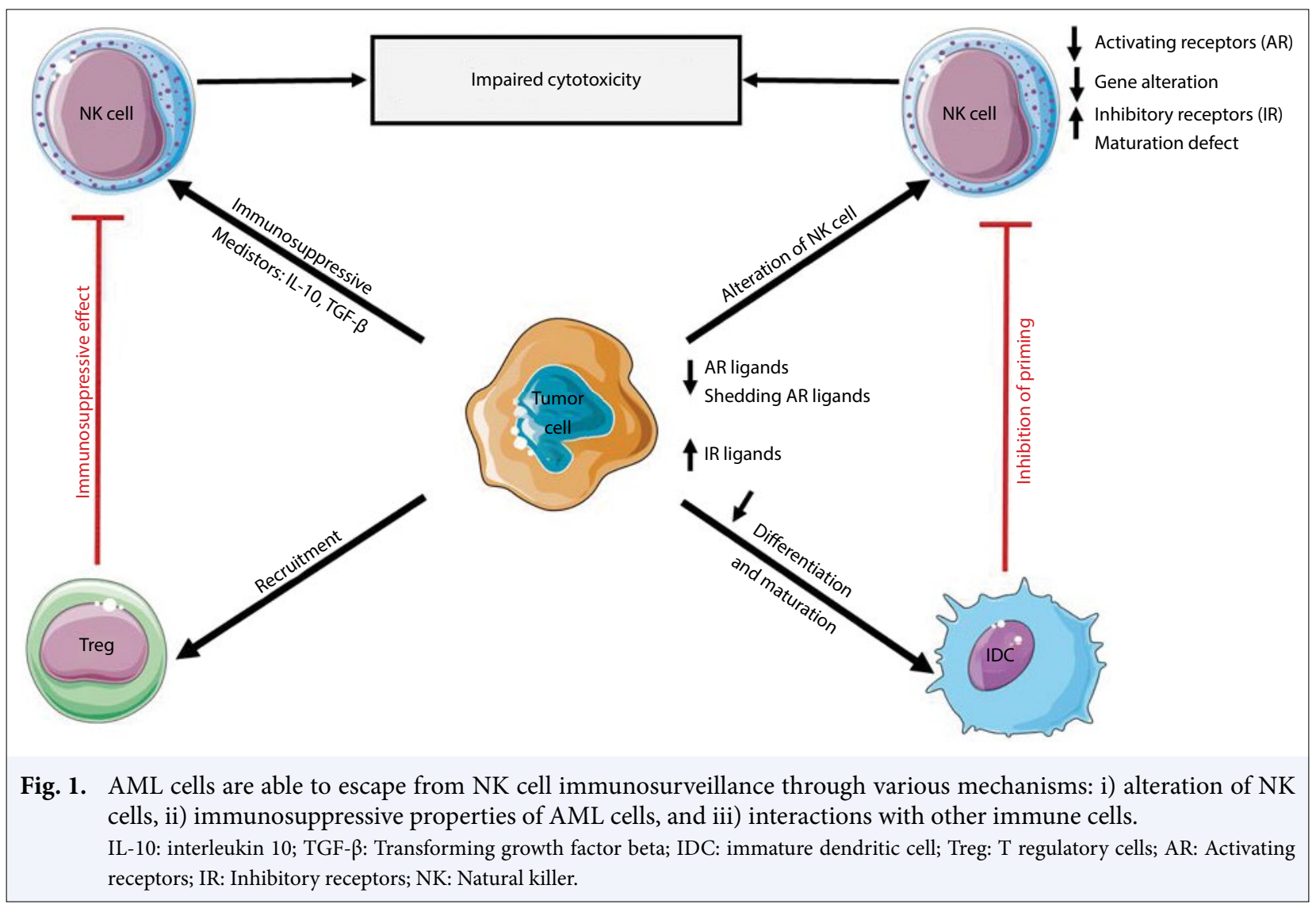

with poor prognosis for AML patients, and significantly lower 5-year survival rates than their $\mathrm{NCR}^{\text {bright }}$ counterparts. Interestingly, the phenotypic and functional abnormalities of NK cells are partially or totally restored in patients achieving remission, which suggest that the presence of AML cells is responsible for NK cells abnormalities.[30] Moreover, Olive's team in 2017 showed a strong correlation between NKp46 expression on NK cells of AML patients at diagnosis and the clinical outcomes after allogeneic stem cell transplantation. They found that patients with high expression of NKp46 at diagnosis had better progression-free survival and overall survival (OS) than patients with low expression of NKp46.[36] Regarding the expression of inhibitory receptors, it is clear that failure to achieve remission in AML patients is strongly associated with overexpression of NKG2A and inhibitory KIRs.[31,33]

\section{Alterations of the Expression of NK Cell Recep- tors Ligands}

Another strategy by which AML can escape from NK cell immunosurveillance is decreasing the expression and shedding of surface ligands for various NK cell activating receptors on AML cells themselves.[34,37-
40] For example, leukemic blasts are characterized by a sharp decrease in the expression of MICA/B and ULBPs (ligands of NKG2D), CD48 (a ligand for 2B4), NCR-specific ligands, and DNAM-1 ligands (CD112/ CD155). $[34,38,39,41,42]$ These alterations were associated with reduction of the effector functions of NK cells and OS among those patients. On other hand, DNAM1 ligands (CD112 and CD155) are highly expressed on AML blasts of patients younger than 65 years. However, NK recognition and killing of leukemic blasts is reduced due to downregulation of DNAM-1 on NK cells of AML patients, hypothesizing a converse relationship between DNAM-1 ligands expression on leukemic blasts and DNAM-1 expression on NK cells. [43] Besides the classical alterations of the expression of NK receptors and their ligands in AML, Olive's team reported alteration in the maturation profile of NK cells in AML patients. They found three different groups of AML patients based on NK maturation profile: hypomaturation, intermediate maturation, and hypermaturation. Interestingly, the findings revealed that patients with hypomaturation profile have decreased OS and relapse-free survival compared to patients with intermediate and hypermaturation.[44] 


\section{Alterations of NK Cell at Genetic Level}

Some attempts were performed at gene level to try to identify the molecular mechanisms of NK functions defect in hematological malignancies. In this context, Costello's team aimed to realize the mechanisms underlying NCRs down-regulation in NK cells from AML patients.[32] They found that AML-NK cells showed a specific transcriptomic signature compared to NK cells from healthy volunteers, disappeared by NK cells expansion. Although the gene expression of E26 transformation-specific 1 (ETS-1) transcription factor (a potential regulatory element of NCRs expression) was decreased in presence of AML blasts, the expression of ETS- 1 and NCRs was restored following AML-NK cells expansion. This proposes that ETS-1 may regulate NCRs expression.[32] In addition, miRNAs, which play an important role in fundamental NK cell biology, [45] can be well accepted to participate in many aspects of AML, including proliferation, differentiation, survival, apoptosis and invasion by targeting oncogenes or tumor suppressors. [46,47] A study showed a selective loss of immature NK cells subset and a clear reduction in the cytolytic granules containing perforin and granzyme B among NK cells in leukemic mice and the NK cells in leukemic mice showed lower levels of T-bet and Eomes, critical transcription factors for terminal NK cell differentiation. They demonstrated that these results are related to miR-29b overproduction, a negative regulator of T-bet and Eomes, in NK cells of leukemic mice because deletion of miR-29b in NK cells reversed these alterations.[48] A recent study found that the expression of CD48 molecule is down-regulated on the surface of NK cells in AML patients.[49] CD48 is expressed on the surface of lymphocytes including NK cells and participates in activation and differentiation pathways in these cells. The results showed that down-regulation of CD48 in AML patients was associated with decreasing the cytotoxic activity of NK cells.[49]

\section{Immunosuppressive Properties of AML Blasts}

Besides the phenotypic and functional alterations of NK cells, AML blasts are able to diminish NK cell immunosurveillance by other immunosuppressive factors. For example, a study found an overexpression of CD137 ligand (CD137L) and glucocorticoid-induced tumor necrosis factor receptor (TNFR)-related protein ligand (GITRL) on AML blasts, where these molecules are ligands for TNFR family.[50,51] Engagement of CD137L and GITRL with their receptors on human NK cells is directly associated with impairing NK cell-mediated killing and IFN- $\gamma$ secretion or indirectly via se- cretion of IL- 10 by AML cells. Oppositely, they showed that both CD137 and GITR mediate a stimulatory signal in mouse NK cells after their binding with CD137L and GITRL, respectively.[50,51] Cytotoxic functions of NK cells are also impaired by TGF- $\beta$, which is secreted by AML blast as well as by regulatory $\mathrm{T}$ (Treg) cells, myeloid derived suppressor cells and other stromal cells in the tumor microenvironment.[52,53]

\section{Alterations of Interaction Between NK Cells and Other Immune Cells}

Cellular interactions between NK cells and other immune cells are also altered in AML patients resulting in more possibilities of immune escape. NK cells play a key role in regulation of DCs by killing immature DCs to limit inflammation and inappropriate $\mathrm{T}$ cell tolerization. Fauriat and his colleagues (2005) have noticed the inability of NK cells from AML patients to kill immature DCs which might result in an abnormal interaction between $\mathrm{T}$ cells and immature DCs and induction of tolerogenic T cells. [54] Further, the number of Treg cells, which are the predominant immune suppressor cells, are increased among AML patients compared to healthy donors, while their numbers are reduced in patients with complete remission (CR).[55]

\section{Restoration of NK Cell Cytotoxic Functions}

Whereas impaired NK cells are associated with the progression of AML, recovery and boosting the effector functions of NK cells are essential for the control and eradication of AML. In general, there are different approaches used to restore and enhance the effectiveness of anti-tumor function of NK cells, including cytokines, monoclonal antibodies (mAbs), and adoptive transfer of NK cells.[14,26,56-59]

\section{Cytokines}

Several cytokines have been confirmed to enhance NK cell proliferation and/or cytotoxicity against several types of tumors. Cytokines are used for this purpose either by direct infusion of cytokines in vivo to boost the autologous NK cell numbers and functions or by in vitro incubation of allogeneic NK cells with cytokines before adoptive NK cell immunotherapy. IL-2 is the first cytokine approved for use in patients to improve NK cells activity, where it restored NK cell receptor expression and increased NK cell activity against autologous AML cells in vitro. [60] However, infusion of IL-2 into patients was accompanied by limited clinical outcomes because 
IL-2 activates not only NK cells but also Treg cells, which express CD25 (high affinity receptor for IL-2) that can compete with NK cells for IL-2, and subsequently suppress their effector function. [61] In addition, IL-15 was used to activate NK cells with less toxicity.[62] IL-15 has been reported to control development, homeostasis and cytotoxicity of NK cells, which can be presented to NK cells in vivo through several cell types, including monocytes, macrophages and DCs. [63] Infusion of IL-15 into patients increased the cell numbers of circulating NK cells and upregulated the expression of the activating NK cell receptor NKp30, which augmented NK cell cytotoxicity in AML patients. [35,64]

\section{mAbs and Checkpoint Inhibitors}

$m A b s$ can realize anti-tumor effects by modifying the activity of their target proteins and by redirecting the effector immune cells to cancer cells. mAbs treatment based on NK cells includes mAbs which target tumorassociated antigens to induce NK cell, and $\mathrm{mAbs}$ which target and block immune checkpoint proteins to enhance NK cell cytotoxicity.[14,26,57] By targeting tumor-associated antigens, a specific immune response can be achieved against the tumor cells. In the case of NK cells, these antibodies directly target tumor-associated antigens and also bind to Fc $\gamma$ RIIIA (CD16a) receptor expressed by NK cells to induce NK-mediated ADCC. Consistent with the meaning, studies showed that monoclonal anti-CD123 antibody (CD123 is overexpressed on AML stem cells showing anti-leukemic activity) improved the binding to CD16a and enhanced the anti-leukemic activity of NK cells against AML xenograft models.[65,66] Further, Koerner et al.[67] (2017) found that an Fc-optimized CD133 antibody had a greater affinity to NK cells and more cytotoxic activity for NK cells without relevant toxicity to hematopoietic progenitors in a human AML xenograft model.

The second strategy based on mAbs to recover NK cell effector functions is using targeted $\mathrm{mAbs}$ to block specific immune checkpoint proteins to enhance the cytotoxic activity of NK cells. One of these inhibitory proteins is NKG2A, an inhibitory receptor expressed in NK cells and binds with HLA-E ligand. The expression of HLA-E is often upregulated in some cancer cells to escape from NK cell cytotoxicity. In addition, NKG2A expression on tumor-infiltrating NK cells has increased in cancer cells.[68,69] As a result, blocking NKG2A by a humanized antibody called monalizumab improves the cytotoxic activity of NK cells in mice engrafted with primary leukemia cells as well as against HLA-E+ target cells. [70,71] Another checkpoint affecting the functional activity of NK cells is programmed cell death protein 1 (PD-1) which was recently discov- ered in a mature CD56 ${ }^{\mathrm{dim}} \mathrm{NK}$ cells where its expression significantly suppresses NK function against PD-1 ligand expressing tumor targets.[72,73] In addition, the expression of programmed cell death ligand-1 (PD-L1) is observed in AML blasts.[74] PD-1 antibodies such as pembrolizumab and nivolumab, preventing PD-1/ PD-L1 interaction, have been developed and their effect to enhance endogenous NK cell cytotoxic function remains attractive.[75] Interestingly, blocking PD-1 or PD-L1 increases the cytotoxic activity of NK cells, and decreases the growth of some tumors in xenograft models.[76,77] In AML, nivolumab in combination with idarubicin and cytarabine decreased the progression of AML in patients with newly diagnosed AML and also increased the OS.[78]

\section{NK Cell-Based Adoptive Immunotherapy}

The strategy of using NK cells as adoptive immunotherapy depends on the valuable effects of NK cell alloreactivity which is induced by the mismatch between HLA class I molecules on recipient cells and KIRs on donor NK cells. Several clinical reports have shown that donor NK cell alloreactivity is a key therapeutic element in the success of transplant and killing leukemia through GvL effect without development of graft versus host disease as well as controlling infections. [79,80] In general, donor-derived NK cells are mainly obtained from donor PBMCs by separating protocols; however, obtaining sufficient numbers of NK cells from PBMCs to achieve a therapeutic effect has been a major limitation.[81] Therapeutically, a phase I clinical trial showed that infusion of IL-15 plus IL-21 stimulated NK cells which were given after hematopoietic stem cell transplantation (HSCT) reduced progression of leukemia compared with patients who have subjected to HSCT without NK cell infusion.[82] Moreover, infusion of multiple doses of NK cells expanded ex vivo with feeder cells was effective in minimizing leukemia relapse. A present study showed that infusion of IL-2 activated NK cells into patients with hematologic malignancies 2 months following HSCT was associated with increasing the expression of activating receptors on the reconstituting NK cells as well as increasing degranulation and cytokine production.[83] After follow-up, a CR of hematologic malignancies was observed in 11 patients out of 16 treated patients.

\section{Conclusion}

NK cells are a specific group of lymphocytes playing a key role in the innate immune responses against virus-infected cells as well as different types of cancer. 
Although NK cells play a major role in immunosurveillance against AML cells, it was demonstrated that NK cells in AML patients have impaired anti-leukemic activity due to multiple mechanisms of innate immune escape, including down-regulation of activating receptors expression, up-regulation of inhibitory NKG2A expression, down-regulation of NK-activating ligands, and secretion of soluble NK-inhibitory factors as well as other immunosuppressant mechanisms. However, the specific molecular mechanisms involved in these alterations are still not well defined. Hence, there is a persistent need for complete understanding of how AML escapes the natural defenses of immune system.

Peer-review: Externally peer-reviewed.

Conflict of Interest: The authors declare no conflicts of interest.

Financial Support: The authors received no financial support for the publication of this article.

\section{References}

1. Caligiuri MA. Human natural killer cells. Blood 2008;112(3):461-9.

2. Vivier E, Tomasello E, Baratin M, Walzer T, Ugolini S. Functions of natural killer cells. Nat Immunol 2008;9(5):503-10.

3. Moretta L, Bottino C, Pende D, Vitale M, Mingari MC, Moretta A. Human natural killer cells: Molecular mechanisms controlling NK cell activation and tumor cell lysis. Immunol Lett 2005;100(1):7-13.

4. Miller JS, Cooley S, Parham P, Farag SS, Verneris MR, McQueen KL, et al. Missing KIR ligands are associated with less relapse and increased graft-versus-host disease (GVHD) following unrelated donor allogeneic HCT. Blood 2007;109(11):5058-61.

5. Ruggeri L, Capanni M, Urbani E, Perruccio K, Shlomchik WD, Tosti A, et al. Effectiveness of donor natural killer cell alloreactivity in mismatched hematopoietic transplants. Science 2002;295(5562):2097-100.

6. Cooper MA, Fehniger TA, Caligiuri MA. The biology of human natural killer-cell subsets. Trends Immunol 2001;22(11):633-40.

7. Vivier E, Raulet DH, Moretta A, Caligiuri MA, Zitvogel L, Lanier LL, et al. Innate or adaptive immunity? The example of natural killer cells. Science 2011;331(6013):44-9.

8. Vivier E. What is natural in natural killer cells? Immunol Lett 2006; 107(1):1-7.

9. Assarsson E, Kambayashi T, Persson CM, Ljunggren
H-G, Chambers BJ. 2B4 co-stimulation: NK cells and their control of adaptive immune responses. Mol Immunol 2005;42(4):419-23.

10. Kalinski P, Giermasz A, Nakamura Y, Basse P, Storkus WJ, Kirkwood JM, et al. Helper role of NK cells during the induction of anticancer responses by dendritic cells. Mol Immunol 2005;42(4):535-9.

11. Smyth MJ, Cretney E, Kelly JM, Westwood JA, Street SEA, Yagita H, et al. Activation of NK cell cytotoxicity. Mol Immunol 2005;42(4):501-10.

12. Long EO, Sik Kim H, Liu D, Peterson ME, Rajagopalan S. Controlling natural killer cell responses: integration of signals for activation and inhibition. Annu Rev Immunol 2013;31(1):227-58.

13. Vivier E, Ugolini S, Blaise D, Chabannon C, Brossay L. Targeting natural killer cells and natural killer $\mathrm{T}$ cells in cancer. Nat Rev Immunol 2012;12(4):239-52.

14. Fang F, Xiao W, Tian Z. NK cell-based immunotherapy for cancer. Semin Immunol 2017;31:37-54.

15. Chavez-Galan L, Arenas-Del Angel MC, Zenteno E, Chavez R, Lascurain R. Cell death mechanisms induced by cytotoxic lymphocytes. Cell Mol Immunol 2009;6(1):15-25.

16. Estey E, Döhner H. Acute myeloid leukaemia. The Lancet 2006;368(9550):1894-907.

17. Tallman MS, Gilliland DG, Rowe JM. Drug therapy for acute myeloid leukemia. Blood 2005;106(4):1154-63.

18. Barrett AJ, Le Blanc K. Immunotherapy prospects for acute myeloid leukaemia. Clin Exp Immunol 2010;161(2):223-32.

19. Lichtenegger FS, Krupka C, Köhnke T, Subklewe M. Immunotherapy for acute myeloid leukemia. Semin Hematol 2015;52(3):207-14.

20. Tang X, Yang L, Li Z, Nalin AP, Dai H, Xu T, et al. Firstin-man clinical trial of CAR NK-92 cells: safety test of CD33-CAR NK-92 cells in patients with relapsed and refractory acute myeloid leukemia. Am J Cancer Res 2018;8(6):1083-9.

21. Dolstra H, Roeven MWH, Spanholtz J, Hangalapura BN, Tordoir M, Maas F, et al. Successful transfer of umbilical cord blood CD34+ hematopoietic stem and progenitor-derived NK cells in older acute myeloid leukemia patients. Clin Cancer Res Off J Am Assoc Cancer Res 2017;23(15):4107-18.

22. Boyiadzis M, Agha M, Redner RL, Sehgal A, Im A, Hou $\mathrm{J}-\mathrm{Z}$, et al. Phase 1 clinical trial of adoptive immunotherapy using "off-the-shelf" activated natural killer cells in patients with refractory and relapsed acute myeloid leukemia. Cytotherapy 2017;19(10):1225-32.

23. Cooley S, He F, Bachanova V, Vercellotti GM, DeFor TE, Curtsinger JM, et al. First-in-human trial of rhIL-15 and haploidentical natural killer cell ther- 
apy for advanced acute myeloid leukemia. Blood Adv 2019;3(13):1970-80.

24. Fehniger TA, Miller JS, Stuart RK, Cooley S, Salhotra A, Curtsinger J, et al. A phase 1 trial of CNDO109-activated natural killer cells in patients with high-risk acute myeloid leukemia. Biol Blood Marrow Transplant J Am Soc Blood Marrow Transplant 2018;24(8):1581-9.

25. Bachanova V, Cooley S, Defor TE, Verneris MR, Zhang B, McKenna DH, et al. Clearance of acute myeloid leukemia by haploidentical natural killer cells is improved using IL-2 diphtheria toxin fusion protein. Blood 2014;123(25):3855-63.

26. Carlsten $M$, Järås $M$. Natural killer cells in myeloid malignancies: immune surveillance, NK cell dysfunction, and pharmacological opportunities to bolster the endogenous NK cells. Front Immunol 2019;10:2357.

27. Xu J, Niu T. Natural killer cell-based immunotherapy for acute myeloid leukemia. J Hematol OncolJ Hematol Oncol 2020;13(1):167.

28. Costello RT, Sivori S, Marcenaro E, Lafage-Pochitaloff M, Mozziconacci M-J, Reviron D, et al. Defective expression and function of natural killer cell-triggering receptors in patients with acute myeloid leukemia. Blood 2002;99(10):3661-7.

29. De Maria A, Fogli M, Costa P, Murdaca G, Puppo F, Mavilio D, et al. The impaired NK cell cytolytic function in viremic HIV-1 infection is associated with a reduced surface expression of natural cytotoxicity receptors (NKp46, NKp30 and NKp44). Eur J Immunol 2003;33(9):2410-8.

30. Fauriat C, Just-Landi S, Mallet F, Arnoulet C, Sainty $\mathrm{D}$, Olive D, et al. Deficient expression of NCR in NK cells from acute myeloid leukemia: evolution during leukemia treatment and impact of leukemia cells in NCRdull phenotype induction. Blood 2007;109(1):323-30.

31. Stringaris K, Sekine T, Khoder A, Alsuliman A, Razzaghi B, Sargeant R, et al. Leukemia-induced phenotypic and functional defects in natural killer cells predict failure to achieve remission in acute myeloid leukemia. Haematologica 2014;99(5):836-47.

32. Venton G, Labiad Y, Colle J, Fino A, Afridi S, Torres $M$, et al. Natural killer cells in acute myeloid leukemia patients: from phenotype to transcriptomic analysis. Immunol Res 2016;64(5-6):1225-36.

33. Khaznadar Z, Boissel N, Agaugué S, Henry G, Cheok $M$, Vignon $M$, et al. Defective NK cells in acute myeloid leukemia patients at diagnosis are associated with blast transcriptional signatures of immune evasion. J Immunol 2015;195(6):2580-90.

34. Sanchez-Correa B, Morgado S, Gayoso I, Bergua JM,
Casado JG, Arcos MJ, et al. Human NK cells in acute myeloid leukaemia patients: analysis of NK cell-activating receptors and their ligands. Cancer Immunol Immunother CII 2011;60(8):1195-205.

35. Szczepanski MJ, Szajnik M, Welsh A, Foon KA, Whiteside TL, Boyiadzis M. Interleukin-15 enhances natural killer cell cytotoxicity in patients with acute myeloid leukemia by upregulating the activating NK cell receptors. Cancer Immunol Immunother CII 2010;59(1):73-9.

36. Chretien A-S, Devillier R, Fauriat C, Orlanducci F, Harbi S, Le Roy A, et al. NKp46 expression on NK cells as a prognostic and predictive biomarker for response to allo-SCT in patients with AML. OncoImmunology 2017;6(12):e1307491.

37. Diermayr S, Himmelreich H, Durovic B, Mathys-Schneeberger A, Siegler U, Langenkamp U, et al. NKG2D ligand expression in AML increases in response to HDAC inhibitor valproic acid and contributes to allorecognition by NK-cell lines with single KIR-HLA class I specificities. Blood 2008;111(3):1428-36.

38. Nowbakht P, Ionescu M-CS, Rohner A, Kalberer CP, Rossy E, Mori L, et al. Ligands for natural killer cellactivating receptors are expressed upon the maturation of normal myelomonocytic cells but at low levels in acute myeloid leukemias. Blood 2005;105(9):361522.

39. Pende D, Spaggiari GM, Marcenaro S, Martini S, Rivera P, Capobianco A, et al. Analysis of the receptor-ligand interactions in the natural killer-mediated lysis of freshly isolated myeloid or lymphoblastic leukemias: evidence for the involvement of the Poliovirus receptor (CD155) and Nectin-2 (CD112). Blood 2005;105(5):2066-73.

40. Salih HR, Antropius H, Gieseke F, Lutz SZ, Kanz L, Rammensee H-G, et al. Functional expression and release of ligands for the activating immunoreceptor NKG2D in leukemia. Blood 2003;102(4):1389-96.

41.Hilpert J, Grosse-Hovest L, Grünebach F, Buechele C, Nuebling T, Raum T, et al. Comprehensive analysis of NKG2D ligand expression and release in leukemia: implications for NKG2D-mediated NK cell responses. J Immunol 2012;189(3):1360-71.

42. Kearney CJ, Ramsbottom KM, Voskoboinik I, Darcy PK, Oliaro J. Loss of DNAM-1 ligand expression by acute myeloid leukemia cells renders them resistant to NK cell killing. Oncoimmunology 2016;5(8):e1196308.

43. Sanchez-Correa B, Gayoso I, Bergua JM, Casado JG, Morgado S, Solana R, et al. Decreased expression of DNAM-1 on NK cells from acute myeloid leukemia patients. Immunol Cell Biol 2012;90(1):109-15.

44. Chretien A-S, Fauriat C, Orlanducci F, Galseran C, Rey 
J, Bouvier Borg G, et al. Natural killer defective maturation is associated with adverse clinical outcome in patients with acute myeloid leukemia. Front Immunol 2017;8:1-11.

45. Leong JW, Sullivan RP, Fehniger TA. microRNA management of NK cell developmental and functional programs. Eur J Immunol 2014;44(10):2862-8.

46. Marcucci G, Mrózek K, Radmacher MD, Garzon R, Bloomfield $\mathrm{CD}$. The prognostic and functional role of microRNAs in acute myeloid leukemia. Blood 2011;117(4):1121-9.

47. Wallace JA, O'Connell RM. MicroRNAs and acute myeloid leukemia: therapeutic implications and emerging concepts. Blood 2017;130(11):1290-301.

48. Mundy-Bosse BL, Scoville SD, Chen L, McConnell $\mathrm{K}$, Mao HC, Ahmed EH, et al. MicroRNA-29b mediates altered innate immune development in acute leukemia. J Clin Invest 2016;126(12):4404-16.

49. Wang Z, Xiao Y, Guan W, Wang M, Chen J, Zhang L, et al. Acute myeloid leukemia immune escape by epigenetic CD48 silencing. Clin Sci 2020;134(2):261-71.

50. Baessler T, Krusch M, Schmiedel BJ, Kloss M, Baltz KM, Wacker A, et al. Glucocorticoid-induced tumor necrosis factor receptor-related protein ligand subverts immunosurveillance of acute myeloid leukemia in humans. Cancer Res 2009;69(3):1037-45.

51. Baessler T, Charton JE, Schmiedel BJ, Grünebach F, Krusch M, Wacker A, et al. CD137 ligand mediates opposite effects in human and mouse NK cells and impairs NK-cell reactivity against human acute myeloid leukemia cells. Blood 2010;115(15):3058-69.

52. Baginska J, Viry E, Paggetti J, Medves S, Berchem G, Moussay E, et al. The critical role of the tumor microenvironment in shaping natural killer cell-mediated antitumor immunity. Front Immunol 2013;4:490.

53. Otegbeye F, Ojo E, Moreton S, Mackowski N, Lee DA, Lima $M$ de, et al. Inhibiting TGF-beta signaling preserves the function of highly activated, in vitro expanded natural killer cells in AML and colon cancer models. PLOS ONE 2018;13(1):e0191358.

54. Fauriat C. Defective killing of dendritic cells by autologous natural killer cells from acute myeloid leukemia patients. Blood 2005;106(6):2186-8.

55. Shenghui Z, Yixiang H, Jianbo W, Kang Y, Laixi B, Yan Z, et al. Elevated frequencies of CD4+ CD25+ CD127lo regulatory $T$ cells is associated to poor prognosis in patients with acute myeloid leukemia. Int J Cancer 2011;129(6):1373-81.

56. Chiossone L, Vienne M, Kerdiles YM, Vivier E. Natural killer cell immunotherapies against cancer: checkpoint inhibitors and more. Semin Immunol 2017;31:55-63.

57. Gauthier M, Laroye C, Bensoussan D, Boura C, De- cot V. Natural Killer cells and monoclonal antibodies: Two partners for successful antibody dependent cytotoxicity against tumor cells. Crit Rev Oncol Hematol 2021;160:103261.

58. Lamb MG, Rangarajan HG, Tullius BP, Lee DA. Natural killer cell therapy for hematologic malignancies: successes, challenges, and the future. Stem Cell Res Ther 2021;12(1):211.

59. Mehta RS, Randolph B, Daher M, Rezvani K. NK cell therapy for hematologic malignancies. Int J Hematol 2018;107(3):262-70.

60. Torelli GF, Guarini A, Palmieri G, Breccia M, Vitale A, Santoni A, et al. Expansion of cytotoxic effectors with lytic activity against autologous blasts from acute myeloid leukaemia patients in complete haematological remission: autologous killing of aml blasts by expanded NK cells. Br J Haematol 2002;116(2):299-307.

61. Rosenberg SA, Lotze MT, Muul LM, Leitman S, Chang AE, Ettinghausen SE, et al. Observations on the systemic administration of autologous lymphokine-activated killer cells and recombinant interleukin-2 to patients with metastatic cancer. $N$ Engl J Med 1985;313(23):1485-92.

62. Wrangle JM, Patterson A, Johnson CB, Neitzke DJ, Mehrotra S, Denlinger CE, et al. IL-2 and beyond in cancer immunotherapy. J Interferon Cytokine Res 2018;38(2):45-68.

63. Floros T, Tarhini AA. Anticancer cytokines: biology and clinical effects of interferon- $\alpha 2$, interleukin (IL)-2, IL-15, IL-21, and IL-12. Semin Oncol 2015;42(4):53948.

64. Sanchez-Correa B, Bergua JM, Pera A, Campos C, Arcos MJ, Bañas $\mathrm{H}$, et al. In vitro culture with interleukin-15 leads to expression of activating receptors and recovery of natural killer cell function in acute myeloid leukemia patients. Front Immunol 2017;8:931.

65. Busfield SJ, Biondo M, Wong M, Ramshaw HS, Lee EM, Ghosh S, et al. Targeting of acute myeloid leukemia in vitro and in vivo with an anti-CD123 mAb engineered for optimal ADCC. Leukemia 2014;28(11):2213-21.

66. Lee EM, Yee D, Busfield SJ, McManus JF, Cummings $\mathrm{N}$, Vairo G, et al. Efficacy of an Fc-modified antiCD123 antibody (CSL362) combined with chemotherapy in xenograft models of acute myelogenous leukemia in immunodeficient mice. Haematologica 2015;100(7):914-26.

67. Koerner SP, André MC, Leibold JS, Kousis PC, Kübler A, Pal M, et al. An Fc-optimized CD133 antibody for induction of NK cell reactivity against myeloid leukemia. Leukemia 2017;31(2):459-69.

68. Mamessier E, Sylvain A, Thibult M-L, Houvenaeghel G, Jacquemier J, Castellano R, et al. Human breast 
cancer cells enhance self-tolerance by promoting evasion from NK cell antitumor immunity. J Clin Invest 2011;121(9):3609-22.

69. Sheu B-C, Chiou S-H, Lin H-H, Chow S-N, Huang $\mathrm{S}-\mathrm{C}$, Ho H-N, et al. Up-regulation of inhibitory natural killer receptors CD94/NKG2A with suppressed intracellular perforin expression of tumor-infiltrating CD8+ T lymphocytes in human cervical carcinoma. Cancer Res 2005;65(7):2921-9.

70. André P, Denis C, Soulas C, Bourbon-Caillet C, Lopez $\mathrm{J}$, Arnoux T, et al. Anti-NKG2A mAb is a checkpoint inhibitor that promotes anti-tumor immunity by unleashing both T and NK cells. Cell 2018;175(7):173143.e13.

71. Ruggeri L, Urbani E, Andre P, Mancusi A, Tosti A, Topini F, et al. Effects of anti-NKG2A antibody administration on leukemia and normal hematopoietic cells. Haematologica 2016;101(5):626-33.

72. Davis Z, Felices M, Lenvik TR, Badal S, Hinderlie P, Blazar BR, et al. PD-1 is expressed at low levels on all peripheral blood natural killer cells but is a significant suppressor of NK function against PD-1 ligand expressing tumor targets. Blood 2019;134(Supplement_1):621.

73. Pesce S, Greppi M, Tabellini G, Rampinelli F, Parolini $S$, Olive $D$, et al. Identification of a subset of human natural killer cells expressing high levels of programmed death 1: A phenotypic and functional characterization. J Allergy Clin Immunol 2017;139(1):335-46.e3.

74. Yang H, Bueso-Ramos C, DiNardo C, Estecio MR, Davanlou $\mathrm{M}$, Geng Q-R, et al. Expression of PD-L1, PDL2, PD- 1 and CTLA4 in myelodysplastic syndromes is enhanced by treatment with hypomethylating agents. Leukemia 2014;28(6):1280-8.

75. Romero D. Immunotherapy: PD-1 says goodbye, TIM3 says hello. Nat Rev Clin Oncol 2016;13(4):202-3.
76. Guo Y, Feng X, Jiang Y, Shi X, Xing X, Liu X, et al. PD1 blockade enhances cytotoxicity of in vitro expanded natural killer cells towards myeloma cells. Oncotarget 2016;7(30):48360-74.

77. Liu Y, Cheng Y, Xu Y, Wang Z, Du X, Li C, et al. Increased expression of programmed cell death protein 1 on NK cells inhibits NK-cell-mediated anti-tumor function and indicates poor prognosis in digestive cancers. Oncogene 2017;36(44):6143-53.

78. Ravandi F, Assi R, Daver N, Benton CB, Kadia T, Thompson PA, et al. Idarubicin, cytarabine, and nivolumab in patients with newly diagnosed acute myeloid leukaemia or high-risk myelodysplastic syndrome: a single-arm, phase 2 study. Lancet Haematol 2019;6(9):e480-8.

79. Ruggeri L, Mancusi A, Burchielli E, Aversa F, Martelli MF, Velardi A. Natural killer cell alloreactivity in allogeneic hematopoietic transplantation. Curr Opin Oncol 2007;19(2):142-7.

80. Suck G, Linn YC, Tonn T. Natural killer cells for therapy of leukemia. Transfus Med Hemotherapy 2016;43(2):89-95.

81. Knorr DA, Bachanova V, Verneris MR, Miller JS. Clinical utility of natural killer cells in cancer therapy and transplantation. Semin Immunol 2014;26(2):161-72.

82. Choi I, Yoon SR, Park S-Y, Kim H, Jung S-J, Jang YJ, et al. Donor-derived natural killer cells infused after human leukocyte antigen-haploidentical hematopoietic cell transplantation: a dose-escalation study. Biol Blood Marrow Transplant 2014;20(5):696-704.

83. Devillier R, Calmels B, Guia S, Taha M, Fauriat C, Mfarrej B, et al. Phase I trial of prophylactic donorderived IL-2-activated NK cell infusion after allogeneic hematopoietic stem cell transplantation from a matched sibling donor. Cancers 2021;13(11):2673. 